\title{
Excitatory Amino Acid Transporter EAAT5 Improves Temporal Resolution in the Retina
}

\author{
Jana Gehlen," Christoph Aretzweiler, ${ }^{*}$ Anja Mataruga, Christoph Fahlke, and Frank Müller
}

https://doi.org/10.1523/ENEURO.0406-21.2021

Molecular and Cellular Physiology (IBI-1), Institute of Biological Information Processing, Forschungszentrum Jülich GmbH, D-52428 Jülich, Germany

\begin{abstract}
Excitatory amino acid transporters (EAATs) remove glutamate from the synaptic cleft. In the retina, EAAT1 and EAAT2 are considered the major glutamate transporters. However, it has not yet been possible to determine how EAAT5 shapes the retinal light responses because of the lack of a selective EAAT5 blocker or EAAT5 knock-out (KO) animal model. In this study, EAAT5 was found to be expressed in a punctate manner close to release sites of glutamatergic synapses in the mouse retina. Light responses from retinae of wild-type (WT) and of a newly generated model with a targeted deletion of EAAT5 (EAAT5 ${ }^{-1}$ ) were recorded in vitro using multielectrode arrays (MEAs). Flicker resolution was considerably lower in EAAT5 ${ }^{-1-}$ retinae than in WT retinae. The close proximity to the glutamate release site makes EAAT5 an ideal tool to improve temporal information processing in the retina by controlling information transfer at glutamatergic synapses.
\end{abstract}

Key words: EAAT5; glutamate transporter; retina

\section{Significance Statement}

Neurons communicate with other neurons at synaptic connections by release of neurotransmitters acting at postsynaptic receptors. Neurotransmitters are removed from the synaptic cleft by transporters. Using the mouse retina as a model for the central nervous system, the role of Excitatory amino acid transporter (EAAT) 5 that functions as glutamate transporter and as glutamate-gated ion channel was investigated in retinal information processing. EAAT5 was found highly localized to the glutamate release site at retinal synapses, suggesting a role in shaping of synaptic responses. In a mouse model devoid of EAAT5, temporal resolution of the retina was severely compromised. The results demonstrate that glutamate transporters like EAAT5 can exert a tremendous effect on information processing in neuronal networks.

Received September 29, 2021; accepted October 16, 2021; First published November 11, 2021.

The authors declare no competing financial interests.

Author contributions: F.M. and C.F. designed research; J.G., C.A., and A.M. performed research; J.G., C.A., and A.M. analyzed data; F.M. and C.F. wrote the paper.

This work was supported by the Deutsche Forschungsgemeinschaft Grant MU-3036/3-3.

*J.G. and C.A. contributed equally to this work.

Correspondence should be addressed to Frank Müller at f.mueller@ fz-juelich.de.

https://doi.org/10.1523/ENEURO.0406-21.2021

Copyright (C) 2021 Gehlen et al.

This is an open-access article distributed under the terms of the Creative Commons Attribution 4.0 International license, which permits unrestricted use, distribution and reproduction in any medium provided that the original work is properly attributed.

\section{Introduction}

Excitatory amino acid transporters (EAATs) are secondary active transporters that belong to solute carrier family 1 (SLC1). EAATs rapidly remove glutamate from the synaptic cleft after its release from presynaptic nerve terminals (Vandenberg and Ryan, 2013; Rose et al., 2018) to terminate glutamatergic synaptic transmission and prevent glutamate excitotoxicity. EAATs function as both glutamate transporters and glutamate-gated anion channels (Machtens et al., 2015; Fahlke et al., 2016). To date, five different EAAT isoforms have been described in mammals (EAAT1-EAAT5). These differ significantly in their glutamate transport rates (Mim et al., 2005; Gameiro et al., 2011), but not in their unitary anion current amplitudes (Torres-Salazar and Fahlke, 2007; Schneider et al., 2014). 
Whereas EAATs $1-3$ are effective glutamate transporters (with glutamate uptake currents that exceed their anion currents), the transport rates of EAAT4 and EAAT5 are smaller; therefore, they are assumed to predominantly function as glutamate-gated anion channels.

Glutamate is the major excitatory neurotransmitter in the mammalian retina, where it is used by photoreceptors in the outer plexiform layer (OPL) and bipolar cells in the inner plexiform layer (IPL). EAAT1 (also called GLAST in the mouse) is expressed at high levels in Müller cells and seems to be responsible for most retinal glutamate reuptake (Derouiche and Rauen, 1995; Rauen et al., 1996, 1997; Lehre et al., 1997; Pow and Barnett, 1999; Izumi et al., 2002; Kugler and Beyer, 2003; Fyk-Kolodziej et al., 2004; Sarthy et al., 2005). EAAT2 (GLT-1) is expressed in photoreceptors and bipolar cells (Rauen et al., 1996, 2004; Harada et al., 1998; both glutamatergic cell types), suggesting a role for EAAT2 in glutamate reuptake and recycling. The retinal distribution and function of EAAT5 are less clear owing to lack of a selective EAAT5 blocker or an EAAT5 knock-out (KO) animal model. EAAT5 has been localized immunohistochemically to both synaptic layers (Fyk-Kolodziej et al., 2004; Wersinger et al., 2006; Tse et al., 2014), but also to the somata of some bipolar, amacrine, and ganglion cells, as well as to photoreceptors, including their inner segments (Pow and Barnett, 2000; Wersinger et al., 2006; Lee et al., 2013). Electrophysiological measurements have also suggested the presence of EAAT5 on the terminals of photoreceptors and rod bipolar cells (Wersinger et al., 2006; Veruki et al., 2006).

In this study, the first genetically modified mouse model $\left(\right.$ EAAT $^{-1-}$ ) with a targeted deletion of the S/c1a7 gene, which encodes EAAT5 was generated and analyzed. The EAAT5 expression pattern was defined in normal mouse retinae using a newly generated monoclonal anti-EAAT5 antibody. EAAT5 was strongly expressed in a punctate manner close to glutamate release sites in both synaptic layers of the mouse retina. This signal was completely lost in the EAAT5 ${ }^{-1}$ retina, confirming the specificity of the antibody. The EAAT5 ${ }^{-1-}$ retina displays normal anatomic and synaptic organization, and features robust light responses in the form of the local field potential (LFP) or ganglion cell spiking under all light regimes. However, flicker resolution was considerably compromised in EAAT5 ${ }^{-1-}$ retina, suggesting that an important role of EAAT5 is to improve temporal resolution in the retina.

\section{Materials and Methods}

\section{Animals}

Wild-type (WT) C57BL/6J and C57BI/6N mice were obtained from Charles River. C57BI/6N-EAAT5 ${ }^{-1-}$ mice were generated by microinjection of the transcription activator-like effector nuclease (TALEN) in fertilized eggs (Cyagen Biosciences). Breeding animals delivered by the company displayed irregular retinal morphology that was observed in the $+/+,+/-$, and $-/-$ genotypes. Mice were back-crossed into the $\mathrm{C} 57 \mathrm{BI} / 6 \mathrm{~J}$ background for nine generations. The resulting mice had normal retinal morphology, and immunohistochemical staining with a variety of retinal markers yielded results identical to WT strains. C57BI/6J-EAAT5 ${ }^{-/-}$and C57BI/6J-EAAT5 ${ }^{+/+}$ mice from heterozygous breeding were used for electrophysiological measurements and immunohistochemistry studies. All animals were kept on a $12 \mathrm{~h}$ light/dark cycle with food and water ad libitum. Zeitgeber time (ZT) of the experiments was 3-8 (ZT0 = 7 A.M.) All experiments were performed in accordance with the German Law for the Protection of Animals and following approval by the regulatory authorities.

\section{Generation of the anti-EAAT5 antibody, 20F12}

A monoclonal antibody against murine EAAT5 was generated using a glutathione S-transferase (GST) fusion protein. An intracellular epitope (C-terminal amino acids 441560) present in all postulated splice variants of rat EAAT5 (Lee et al., 2013) was chosen to ensure the detection of all potential murine variants. The amino acid sequence was: tddinliiavdwaldrfrtminvlgdalaagimahicrkdfaqdmgtekllpcetkpvtlqeivaaqqngcvksvaeaseltlgptcphhipvqveqdedpaaasldhctieiseletnv.

Rats (strain: Lou/C) were immunized with the GSTfusion construct using standard procedures (R. Feederle, Antibody Core Facility, Helmholtz Zentrum München), and spleen cells were fused to a mouse myeloma cell line (P3X63-Ag8.653) to generate hybridoma cells. The primary supernatant was tested by ELISA and then immunochemically. Hybridoma cells were subcloned via singlecell distribution until all reacted positively. The final clone was expanded and used to generate supernatant containing the monoclonal antibody (20F12; subtype $\operatorname{lgG}_{2}$ ).

\section{Immunohistochemistry \\ Sections}

For immunohistochemistry, animals were deeply anesthetized with isoflurane and killed by decapitation. The eyes were then enucleated and opened by an encircling cut at the limbus. Eyecups with the retinae were immersion-fixed for $30 \mathrm{~min}$ in $4 \%$ paraformaldehyde in $0.1 \mathrm{M}$ phosphate buffer, pH 7.4 (PB) at room temperature (RT) and then washed in PB several times. The tissue was incubated in $10 \%$ sucrose in PB for $1 \mathrm{~h}$, and then in $30 \%$ sucrose in PB overnight. Retinae were then isolated from the eyecups, flat embedded and frozen in optimal cutting temperature compound (NEG-50, Richard Allen Scientific, Thermo Fisher Scientific). Vertical sections (i.e., perpendicular to the retinal layers, $20-\mu \mathrm{m}$ thick) were cut on a cryostat (HM 560 CryoStat, Microm), collected on SuperFrost Plus slides (Menzel), and stored at $-20^{\circ} \mathrm{C}$.

\section{Dissociated cells}

Eyes were prepared as described above. Retinae of one animal were removed from the eyecups, washed in 1 $\mathrm{ml}$ warm calcium/magnesium-free HBSS (CMF-HBSS; Sigma Aldrich) for $5 \mathrm{~min}$ at $37^{\circ} \mathrm{C}$, and incubated for $20 \mathrm{~min}$ at $37^{\circ} \mathrm{C}$ in $1-\mathrm{ml}$ warm papain (Worthington) solution $(20$ units of papain in 1-ml CMF-HBSS). Papain action was stopped by washing the retinae twice in warm HBSS. The tissue was gently dissociated in $1 \mathrm{ml}$ fresh HBSS by 
Table 1: Primary antibodies and markers

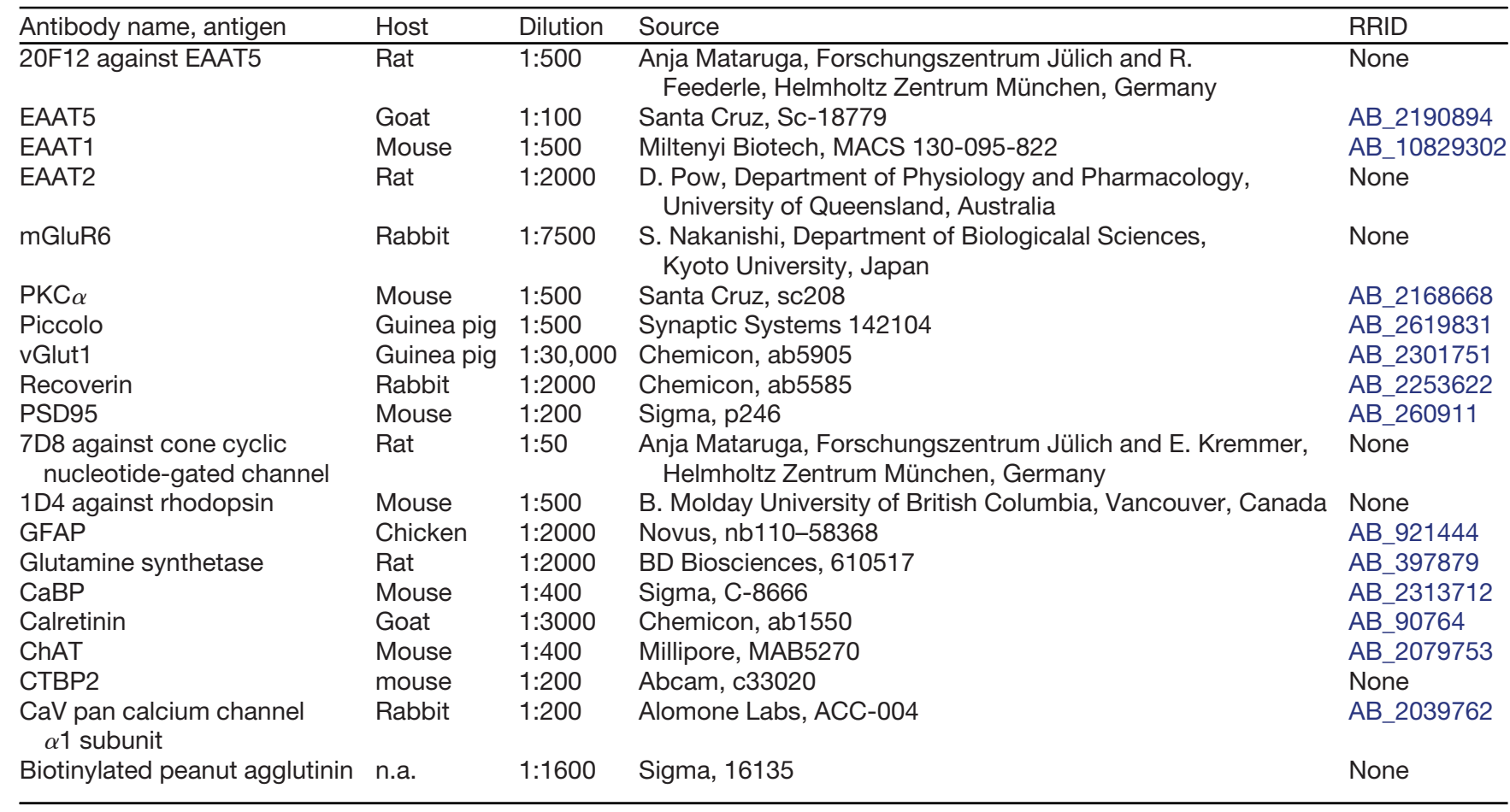

pipetting 15-20 times using a cut and fire-polished 1000$\mu \mathrm{l}$ plastic tip (Nerbe plus). After dissociation, cells were seeded and settled for $30 \mathrm{~min}$ on poly-L-lysine-coated (Sigma) coverslips at RT in a humidified chamber before fixation ( $5 \mathrm{~min}$ at RT with $4 \%$ paraformaldehyde). The fixative was then removed and cells were washed in PB (twice for 10 min each).

\section{Antibody staining}

For anti-EAAT5 antibody (20F12) staining, an antigen retrieval step was performed: 5-min pretreatment with $1 \%$ SDS (AppliChem) in phosphate-buffered saline, followed by three 5-min washes in PB at RT. Sections were incubated overnight at RT with primary antibody diluted in 5\% Chemiblocker (Chemicon), $0.5 \%$ Triton X-100, and $0.05 \% \mathrm{NaN}_{3}$ in PB. Sections were washed in PB, incubated for $1 \mathrm{~h}$ at RT with fluorescently labeled secondary antibody diluted in PB containing 5\% Chemiblocker and $0.5 \%$ Triton $\mathrm{X}-100$, and then washed in PB. The $20 \mathrm{~F} 12$ antibody (rat $\lg G_{2}$ subtype) was detected with secondary mouse anti-rat-lgG2 antibody (gift of R. Feederle, Helmholtz Zentrum München; 1:100 in CTA; $1 \mathrm{~h}$ at RT) and visualized with donkey-anti-mouse Cy3 antibody. Retinal sections were then mounted on coverslips using Aqua-Poly/Mount (Polysciences). Sections and cells were examined using a confocal laser scanning microscope (Leica TCS SP5, Leica Microsystems) with a $63 \times / 1.4$ oil immersion lens. Images were processed using Adobe Photoshop.

Primary antibodies are listed in Table 1.

Secondary antibodies are listed in Table 2. Streptavidin Alexa Fluor 647 (Invitrogen), at 1:100 dilution, was used to visualize biotinylated peanut agglutinin.

\section{Multielectrode arrays (MEAs) and data recording}

MEAs (Multi Channel Systems MCS GmbH) had 60 active electrodes in an $8 \times 8$ matrix layout with electrode diameters (ø) of $30 \mu \mathrm{m}$ and interelectrode distances of $200 \mu \mathrm{m}$. Electrodes were coated with porous titanium nitride with impedance levels of $50 \mathrm{k} \Omega$ at $1 \mathrm{kHz}$. MEAs were pretreated in a plasma cleaner (Diener Electronic $\mathrm{GmbH}$ + Co KG) and coated with poly-D-lysine hydrobromide (Sigma).

The MEA60 data acquisition system (MC_Card, Multichannel System) consisted of an RS-232 interface, an integrated preamplifier and MEA 1060 bandpass filter (amplification gain: 1200), and a personal computer. The waveforms were recorded with a sampling frequency rate of $25 \mathrm{kHz} /$ channel. Data were later converted to ASCII files by MC_Data for further analysis with OriginPro8 and custom-made MATLAB scripts.

\section{Table 2: Secondary antibodies and markers}

\begin{tabular}{|c|c|c|c|}
\hline Antibody & Host & Dilution & Source \\
\hline Anti-rabbit Cy2 & Donkey & $1: 400$ & Dianova \\
\hline Anti-rabbit Cy3 & Donkey & $1: 500$ & Dianova \\
\hline Anti-rabbit Cy5 & Donkey & $1: 500$ & Dianova \\
\hline Anti-mouse Cy2 & Donkey & $1: 100$ & Dianova \\
\hline Anti-mouse Cy3 & Donkey & $1: 100$ & Dianova \\
\hline Anti-mouse Cy5 & Donkey & $1: 200$ & Dianova \\
\hline Anti-chicken Cy2 & Donkey & $1: 200$ & Dianova \\
\hline Anti-rat Cy3 & Donkey & $1: 500$ & Dianova \\
\hline Anti-guinea pig Dy649 & Donkey & $1: 500$ & Dianova \\
\hline Anti-guinea pig Cy2 & Donkey & $1: 400$ & Dianova \\
\hline Anti-goat Cy3 & Donkey & $1: 1000$ & Dianova \\
\hline Anti-goat A647 & Donkey & $1: 200$ & Dianova \\
\hline Streptavidin Alexa Fluor 647 & n.a. & $1: 100$ & Molecular Probes \\
\hline
\end{tabular}


Retinae of adult WT and EAAT5 ${ }^{-1-}$ mice were prepared for MEA recordings. Briefly, mice were dark-adapted overnight. Retina preparation and recording were performed in dim red light. Mice were deeply anesthetized with isoflurane and killed by decapitation. The eyeballs were enucleated and retinae were isolated in carbonatebuffered Ames' solution (Sigma), bubbled with $95 \% \mathrm{O}_{2}+$ $5 \% \mathrm{CO}_{2}$ at a pH of $\sim 7.4$ (AMES). Retinae were cut in half and stored in AMES in the dark at RT. For the experiment, one half retina was transferred with the ganglion cell side up onto a nitrocellulose filter (pore size $0.8 \mu \mathrm{m}$, MFMillipore Membrane Filters, Millipore, size $5 \times 5 \mathrm{~mm}$ with a central hole of 2-mm diameter). The filter/retina sandwich was transferred onto an inverted Petri dish, excess buffer was removed with filter paper, and the sandwich was mounted with the ganglion cells toward the electrode side of the MEA. During recording, the retina was continuously perfused with AMES at a flow rate of $3 \mathrm{ml} / \mathrm{min}$ at RT.

\section{Light stimulation and analysis}

Retinae were stimulated in full-field mode using a white LED (ANSI white, $3465 \mathrm{~K}, 185 \mathrm{Im}$ at $700 \mathrm{~mA}$, rise and fall time of $\sim 100 \mu \mathrm{s}$ ) positioned below the MEA. Stimuli were generated by an external stimulator (STG 4002, Multi Channel Systems MCS GmbH) controlled by MC-Stimulus software. Each light flash was $20 \mathrm{~ms}$ in length. Flicker stimuli were either applied with increasing frequency at a single light intensity or at a single frequency with rising intensity. Intensities were calculated as rhodopsin isomerizations per rod and flash (rhod $*$ $\mathrm{rod} /$ flash), according to Wyszecki and Stiles (2000) and Lyubarsky et al. (2004). Scotopic and mesopic stimuli were applied without background light. For photopic stimulation, the retina was light-adapted on the MEA by a background light of $10,000 \mathrm{rhod}^{\star} / \mathrm{rod} / \mathrm{s}$ for $10 \mathrm{~min}$ (Seeliger et al., 2011) and photopic stimuli were applied on that background. Recordings of both LFP and action potentials were subjected to Fast Fourier Analysis using scripts in Neuroexplorer or MATLAB. The response was considered correct when the dominant peak in the FFT matched the stimulus frequency. The fraction of correct responses (normalized to the response at $2 \mathrm{~Hz}$ ) were plotted against stimulus frequencies.

\section{Results}

\section{Targeted EAAT5 deletion does not affect retinal anatomy or synaptic organization}

Mice carrying a homozygous deletion of S/c1a7 developed normally and were viable. They were fertile with normal mating efficiency and no apparent behavioral deficit or disorder. No anatomic differences were observed between WT (Fig. 1, WT, left) and EAAT5 ${ }^{-1-}$ retinae (KO, right) in retinal thickness or layering (Fig. $1 A$ ). In addition, immunohistochemical staining patterns were similar between genotypes for markers (for details, see legend to Fig. 1) of photoreceptors (Fig. 1B), glia cells (Fig. 1C), neurons of the inner retinal network (Fig. 1D), and presynaptic and postsynaptic elements of photoreceptor synapses (Fig. 1E,F).

\section{EAAT5 is expressed in a punctate manner at glutamatergic synapses}

Although no EAAT5 splice variants have been reported in the mouse, several have been described in the rat (Lee et al., 2013). Therefore, a monoclonal antibody was raised against mouse EAAT5 using a C-terminal epitope homologous to a region common to all rat EAAT5 splice variants to ensure broad specificity for all potential EAAT5 splice forms in the mouse.

EAAT5 was highly localized in WT retinae, often to small puncta in the IPL and OPL (Fig. 2A, arrows). In the inner nuclear layer, some weakly labeled bipolar cell somata (arrowhead) were occasionally visible, with their processes projecting into the IPL. In Figure $2 A$, asterisks mark blood vessels that were nonspecifically labeled by secondary antibodies (the signal was also present in negative controls; data not shown). Importantly, punctate staining was only observed in WT but not in EAAT5 ${ }^{-/-}$retinae, indicating the high specificity of the antibody (Fig. $2 A$, right).

Genetic ablation of EAAT5 did not change the expression patterns of EAAT1 (GLAST; Fig. 2B) or EAAT2 (GLT1; Fig. 2C). Consistent with previous studies in the rat (Derouiche and Rauen, 1995; Rauen et al., 1996), strong EAAT1 staining was found in Müller cell somata and their processes spanning the retina vertically. EAAT2 staining was localized to the somata and processes of photoreceptors (mostly cones) and bipolar cells (Rauen et al., 1996; Harada et al., 1998).

Figure $2 D-J$ shows the close association of EAAT5positive puncta with the glutamate release site on photoreceptors. Photoreceptor terminals comprise one (rod spherule) or several (cone pedicle) invaginations, each with a ribbon structure marking the glutamate release site and three to four postsynaptic processes formed by the dendrites of ON-bipolar and horizontal cells (Dowling and Boycott, 1966). Triple labeling was performed of EAAT5, metabotropic glutamate receptor 6 (mGluR6; the glutamate receptor expressed postsynaptically in ON-bipolar cell dendrites; Nomura et al., 1994), and the presynaptic protein piccolo. In the OPL, the anti-piccolo antibody labeled the ribbons of rods and cones (Regus-Leidig et al., 2013). In Figure 2D, several rod spherules (arrowheads) and two cone pedicles (arrow) could be distinguished. Figure $2 E-J$ show the terminals at higher magnification. Depending on the viewing angle, the rod ribbon (blue) appeared as a line, a horseshoe shape, or an intermediate shape. The number of EAAT5 puncta per spherule seemed to depend on the viewing angle, with one punctum (Fig. 2E) or two puncta (Fig. 2F) between the mGluR6 and piccolo labels (Fig. $2 G, J$, arrows) or with an additional third punctum between the two mGluR6 puncta on the rod bipolar cell dendrites, these sometimes overlapped slightly but never clearly colocalized (Fig. 2G,J, arrowheads).

Multiple EAAT5 puncta might indicate EAAT5 expression by different cell types. First, the puncta might represent the tips of horizontal cells (Dowling and Boycott, 1966). However, in double labeling experiments with antibodies against the calcium-binding protein (CabP)28K (a 


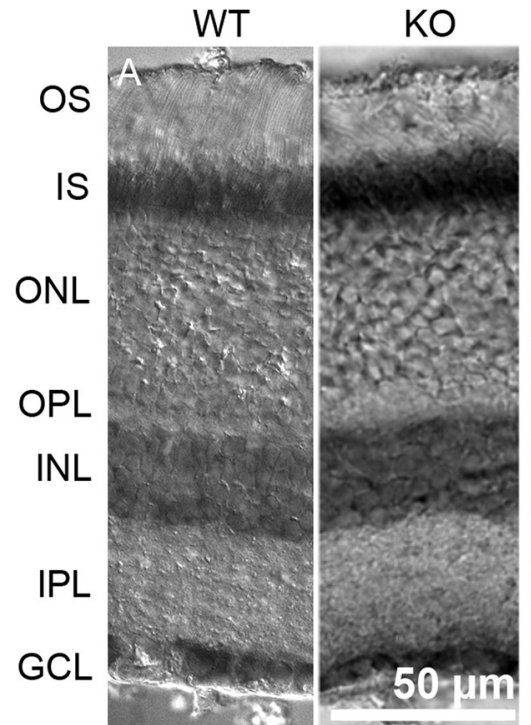

Nissl

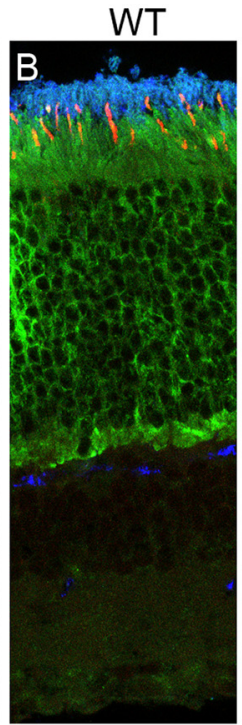

rec cone CNG rhod

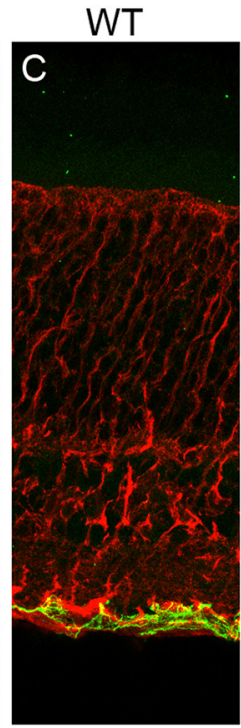

GFAP

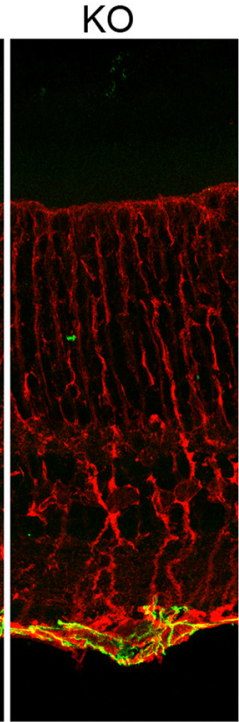

GS

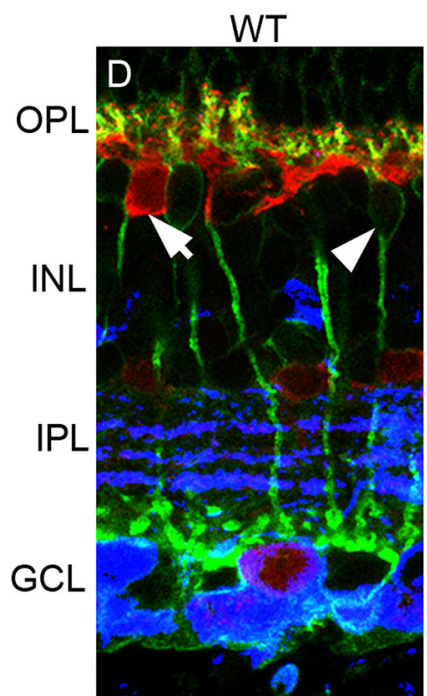

PKCa CabP

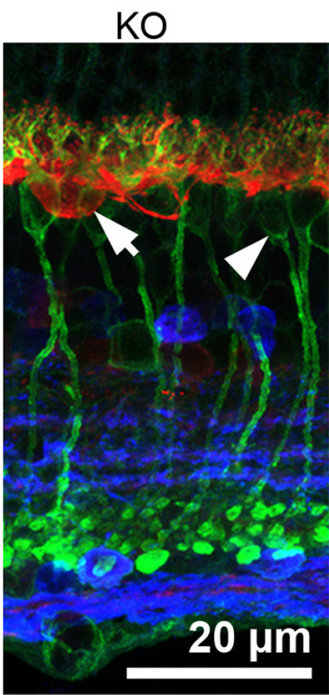

Cal

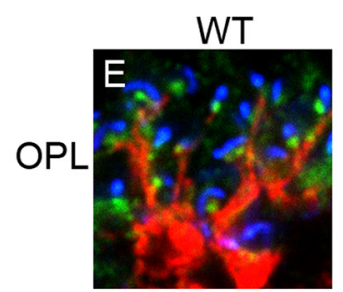

mGluR6 PKCa Pic

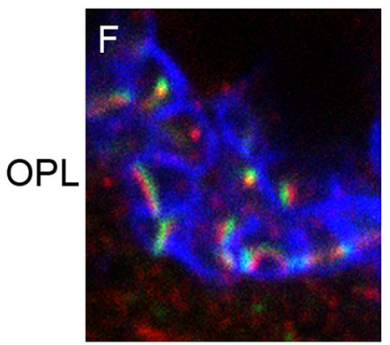

Pic $\quad \alpha 1$

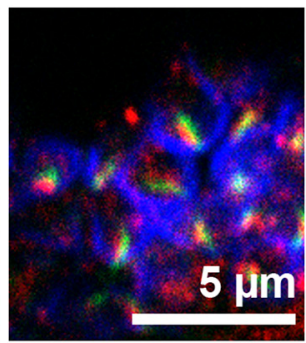

PSD95

Figure 1. The EAAT5 ${ }^{-1-}$ retina appears histologically normal. $\boldsymbol{A}-\boldsymbol{F}$, left, WT retina (WT), right: EAAT5 ${ }^{-1-}$ retina (KO). $\boldsymbol{A}$, Nissl staining reveals retinal thickness and retinal layering. $\boldsymbol{B}$. Photoreceptors, recoverin (rec; green, photoreceptor somata and inner segments), cone cyclic nucleotide-gated (CNG) channel (red, cone outer segments), rhodopsin (rhod; blue, rod outer segments). C, Glial cells, glutamine synthetase (GS; red, Müller cells), glial fibrillary acidic protein (GFAP; green, astrocytes). D, Inner retinal cells, PKC $\alpha$ (green, rod bipolar cells, arrowheads), CabP (red, horizontal cells, arrows), calretinin (Cal; blue, several types of amacrine cells). $\boldsymbol{E}$, OPL, mGluR6 (green, glutamate receptor on ON-bipolar cell dendrites), PKC $\alpha$ (red, rod bipolar cell dendrites), piccolo (Pic; blue, photoreceptor presynaptic ribbon). $\boldsymbol{F}$, OPL, piccolo (Pic; green, photoreceptor presynaptic ribbon), pan $\alpha 1$ calcium channel subunit (red, calcium channel in rod photoreceptors), postsynaptic density protein 95 (PSD95; blue, plasma membrane marker for rod terminals). GCL: ganglion cell layer, INL: inner nuclear layer, IPL: inner plexiform layer, IS: inner segments, ONL: outer nuclear layer, OPL: outer plexiform layer, OS: outer segments. Scale bar in $\boldsymbol{A}$ also applies to $\boldsymbol{B}, \boldsymbol{C}$. WT and EAAT5 ${ }^{-1-}: n=6$ animals.

good marker for horizontal cell dendritic tips; Haverkamp and Wässle, 2000), no colocalization with EAAT5 was observed (data not shown). Second, EAAT5 might localize to a more distal site than mGluR6 on ON-bipolar cell dendrites; however, colocalization with typical rod bipolar cell markers such as protein kinase C (PKC) $\alpha$ or $\mathrm{G} \alpha_{0}$ was not observed. Finally, EAAT5 might be expressed presynaptically in the photoreceptor terminal, with its localization restricted to parts of the plasma membrane within the invagination. Evidence for EAAT5 expression in photoreceptors comes from other studies (Eliasof and Werblin, 1993; Picaud et al., 1995; Pow and Barnett, 2000; Wersinger et al., 2006; Hasegawa et al., 2006; Lee et al., 2013). Cone pedicles harbor several invaginations: Figure $2 H, I$ shows cone pedicles in the side (Fig. $2 H$ ) and top (Fig. 2l) views. Similar to in rod spherules, EAAT5 was found closely associated (but never colocalized) with the ribbons and mGluR6. 

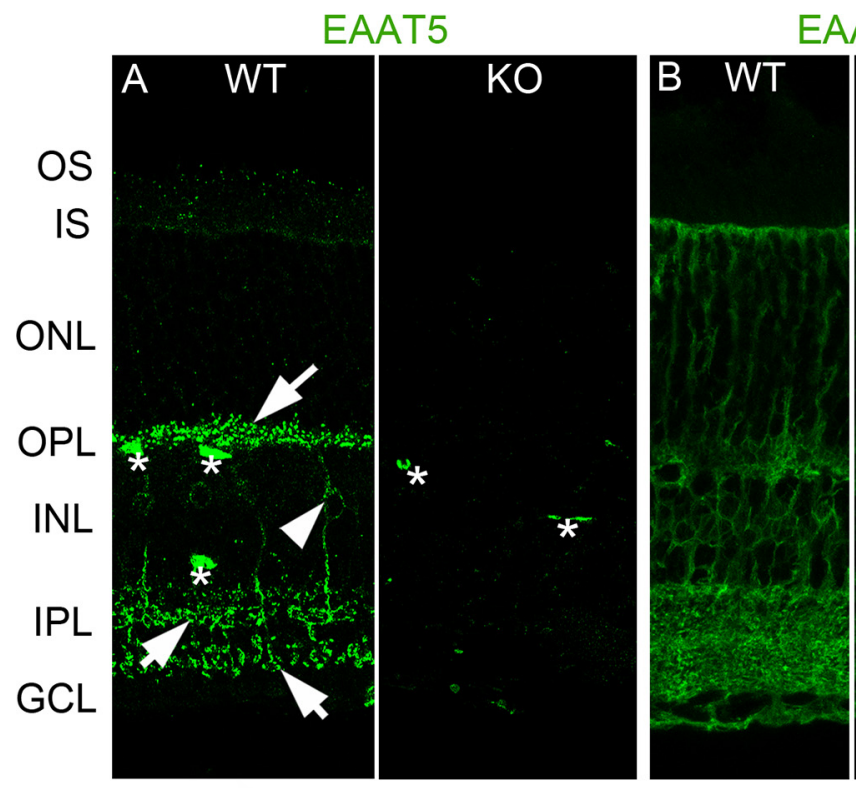

EAAT1

EAAT2
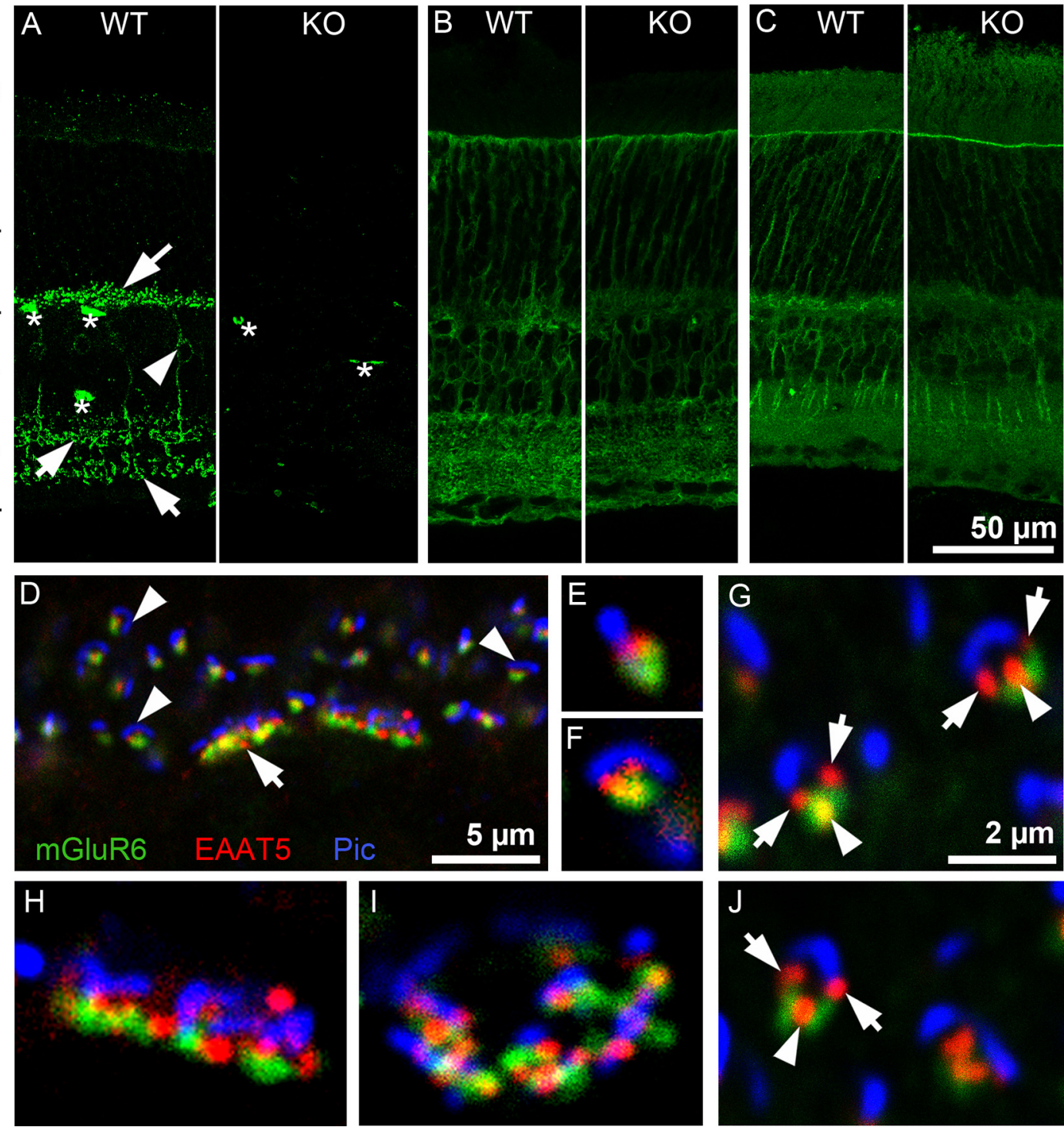

Figure 2. Localization of EAATs in mouse retinal sections. A, EAAT5 expression. In WT retina (left), arrows indicate brightly labeled puncta or short processes in the OPL and IPL, the arrowhead indicates bipolar cell soma in the INL, and asterisks indicate nonspecific staining of blood vessels by the secondary antibody ( $n=10$ animals). In EAAT5 ${ }^{-1-}$ (KO) retina (right), puncta are absent; only nonspecific staining in blood vessels is seen ( $n=5$ animals). $\boldsymbol{B}$, EAAT1 (GLAST) was strongly expressed in Müller cells that span almost all retinal layers. No difference in expression pattern or level was observed in the EAAT5 ${ }^{-1}$ retina (right; $n=3$ animals for WT and for EAAT5 $\left.{ }^{-\prime}\right)$. C, EAAT2 (GLT1) was mainly expressed in photoreceptors and bipolar cells, with no differences in expression between WT (left) and EAAT5 ${ }^{-1-}$ (right) retinae $\left(n=3\right.$ animals for WT and for EAAT5 $\left.{ }^{-1-}\right)$. D-J, Triple staining with antibodies against mGluR6, EAAT5, and piccolo (Pic) in a WT retina ( $n=5$ animals). $\boldsymbol{D}$, In the OPL, EAAT5 (red) is closely associated with both the piccolo-positive ribbon (blue) of photoreceptors, and the mGluR6 label on ON-bipolar cell dendrites (green). Arrow, cone terminal; arrowheads, rod terminals. $\boldsymbol{E}-\mathbf{G}, \boldsymbol{J}$, Higher magnification of rod spherules at different viewing angles, showing EAAT5-positive puncta (red) marked with arrows between the ribbon (blue) and mGluR6 (green) and marked with arrowheads between mGluR6 puncta. $\boldsymbol{H}$, $\boldsymbol{I}$, Single cone pedicles, showing close association of EAAT5-positive puncta with both ribbons and mGluR6. GCL: ganglion cell layer, INL: inner nuclear layer, IPL: inner plexiform layer, IS: inner segments, ONL: outer nuclear layer, OPL: outer plexiform layer, OS: outer segments. The scale bar in $\boldsymbol{C}$ also applies to $\boldsymbol{A}, \boldsymbol{B}$; the scale bar in $\boldsymbol{G}$ also applies to $\boldsymbol{E}, \boldsymbol{F}, \boldsymbol{H}-\boldsymbol{J}$.

Several EAAT5-positive bands could be observed in the IPL (Fig. 2A). At higher magnification (Fig. 3A), triple labeling showed the fine detail of EAAT5 (red) localization relative to vesicular glutamate transporter 1 (vGlut1; green; labels all bipolar cell terminals; Haverkamp et al., 2003) and choline acetyltransferase (ChAT; blue; labels bands of cholinergic processes that subdivide the IPL in a characteristic manner; Haverkamp and Wässle, 2000). Decoration of bipolar cell terminals (green) with numerous EAAT5-positive puncta (white ellipses) was commonly seen in sublaminae (SL) 4 and SL5 but rarer in the other SL. Most terminals in SL4 and SL5 originate from rod 

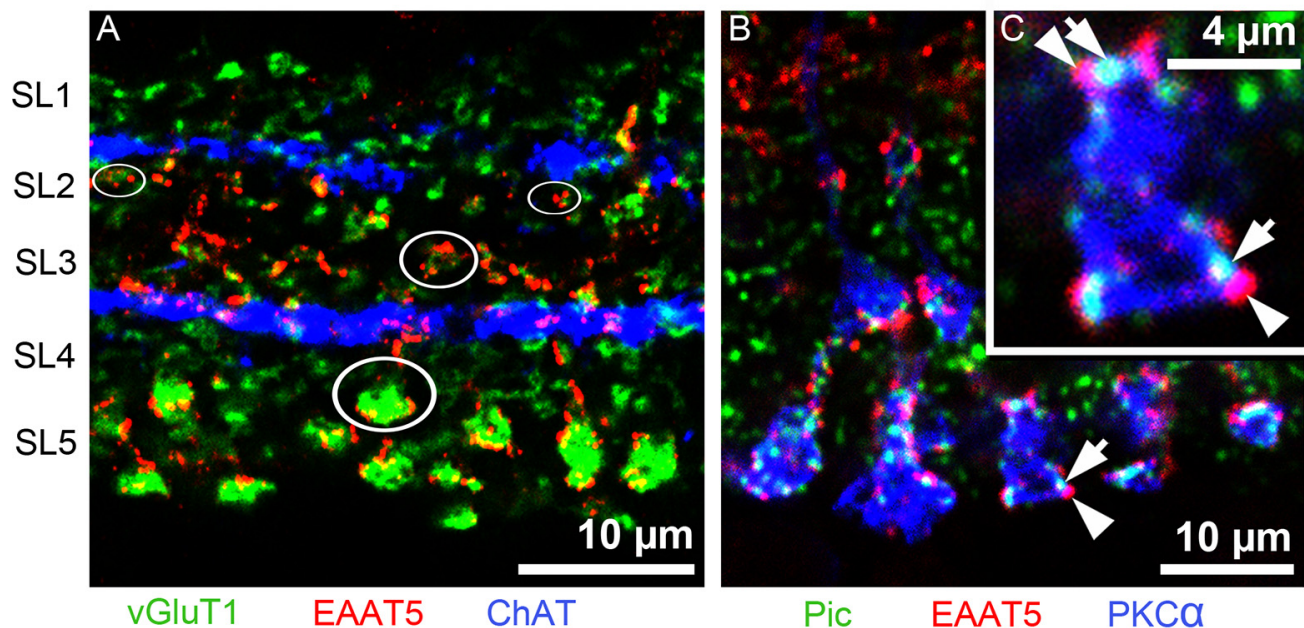

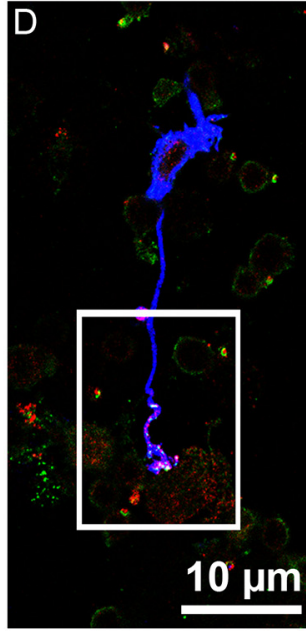

CTBP2

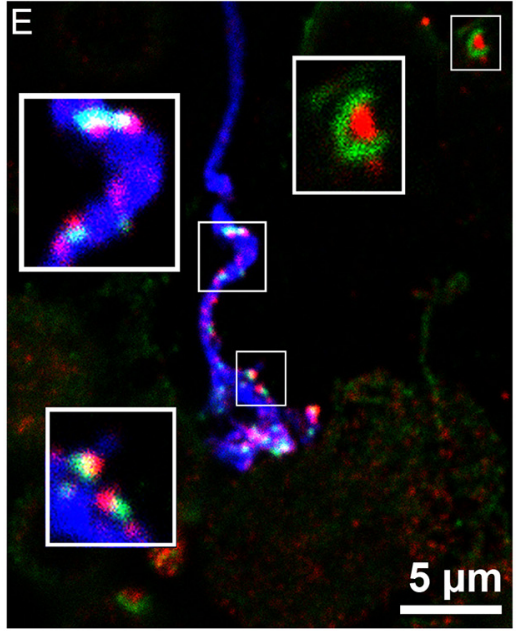

EAAT5 PKC $\alpha$

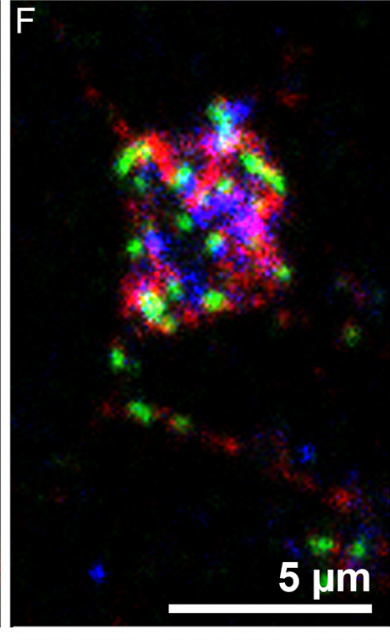

CTBP2 EAAT5 PEA

Figure 3. Localization of EAAT5 on bipolar cell terminals in the mouse retina. $\boldsymbol{A}$, Triple staining. EAAT5-positive puncta (red) were mostly found on vGluT1-positive (green) bipolar cell terminals in SL4 and SL5. ChAT-positive processes (blue) subdivide the IPL in a characteristic way ( $n=3$ animals). $\boldsymbol{B}, \boldsymbol{C}$, Triple staining. Close association of EAAT5-positive puncta (red, arrowheads) and ribbons [piccolo (Pic), green, arrows] on rod bipolar terminals (PKC $\alpha$, blue; $n=6$ animals). $\boldsymbol{D}-\boldsymbol{F}$, Acutely dissociated rod bipolar cells and photoreceptor terminals (three experiments, two retinae of one animal/experiment). $\boldsymbol{D}$, Dissociated rod bipolar cell (PKC $\alpha$, blue) with an axon terminal decorated with EAAT5 (red) puncta and ribbons (CTBP2, green). $\boldsymbol{E}$, Axon terminal of the same cell. Insets are at higher magnification. Top right corner, Isolated rod terminal with horseshoe-shaped ribbon (CTBP2, green) and EAAT5 puncta (red). $\boldsymbol{F}$, Isolated cone terminal [PEA (peanut agglutinin), blue] with closely associated ribbons (CTBP2 green) and EAAT5 puncta (red).

bipolar cells. Therefore, retinal sections were triple labeled for piccolo (green), EAAT5 (red), and PKC $\alpha$ (blue; to label rod bipolar cell terminals; Fig. 3B,C; Negishi et al., 1988; Greferath et al., 1990). Note that in the IPL, piccolo is also present in conventional synapses and, therefore, is seen outside bipolar cell terminals (Regus-Leidig et al., 2013). Nevertheless, ribbons of rod bipolar terminals can be easily identified by their close association with the PKC signal. As seen in photoreceptor invaginations, EAAT5 puncta were in close proximity to the glutamate release site of rod bipolar terminals marked by piccolo-positive ribbons (Fig. 3C, blue).

Owing to the resolution limits of light microscopy, it is difficult to unequivocally distinguish presynaptic and postsynaptic sites at a synapse in retinal sections. Therefore, cells from mouse retinae were isolated by enzymatic digestion. In the cell preparation, EAAT5 puncta were observed on the axon terminals of acutely dissociated rod bipolar cells, again in close proximity to the ribbons (Fig. 3D,E). Isolated rod and cone terminals were also found with similar EAAT5 and ribbon labeling to that seen in intact sections (compare Figs. $3 E$ and $2 F$ and Figs. $3 F$ and $2 /$ ). These staining patterns suggest that EAAT5 is expressed on rod bipolar cell terminals and photoreceptor terminals, in agreement with previous studies (Fyk-Kolodziej et al., 2004; Veruki et al., 2006; Wersinger et al., 2006; Tse et al., 2014).

These results demonstrate that EAAT5 is closely associated with glutamatergic synapses in both synaptic layers of the retina, where it is perfectly located to mediate glutamate-driven negative feedback. Other than loss of the EAAT5 signal, no differences in marker staining were 
A
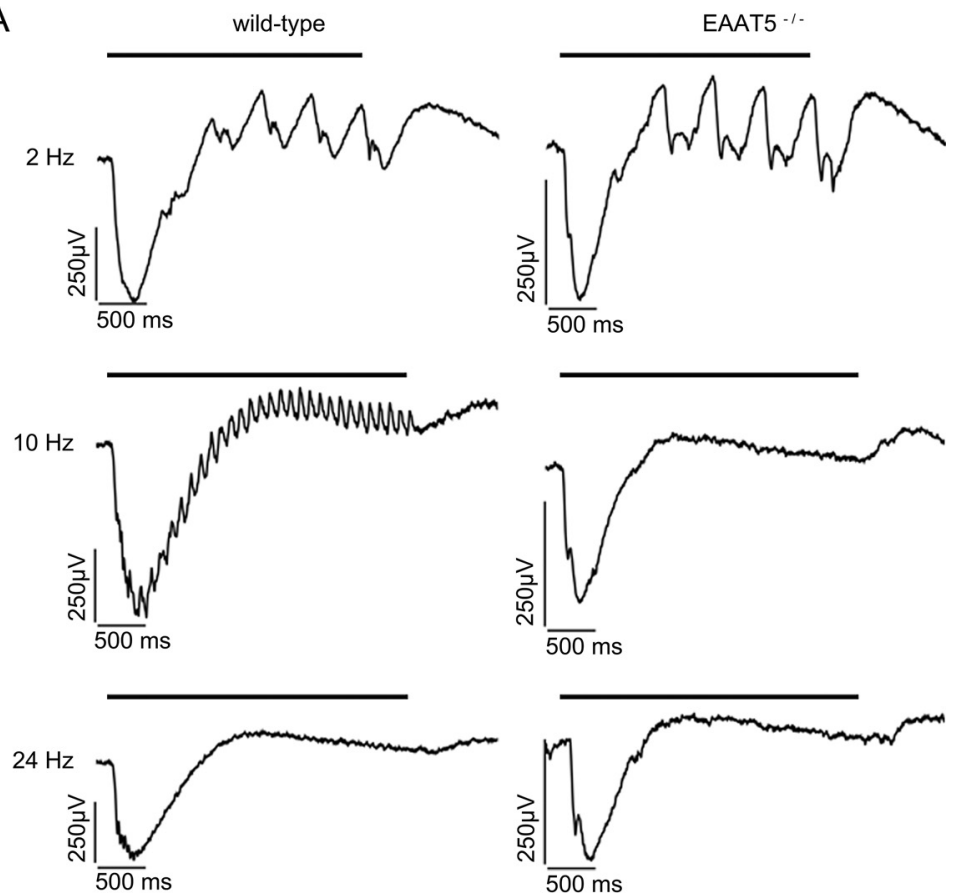

B

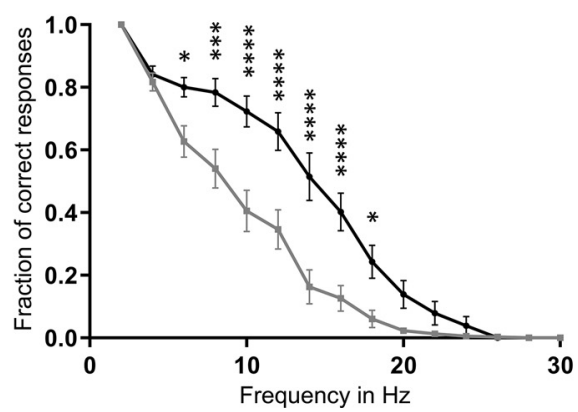

Figure 4. Temporal resolution of the EAAT5 ${ }^{-1-}$ retina is significantly impaired in the mesopic range. Flicker stimuli were applied for a series of frequencies from 2 to $30 \mathrm{~Hz}$. A . The LFP of the EAAT5 ${ }^{-/-}$retina (right) showed impaired resolution for the 10-Hz flicker stimulus compared with the WT retina (left). In neither genotype could the 24-Hz flicker stimulus be resolved. Bars: duration of flicker stimulus. $\boldsymbol{B}$, When the fraction of correct responses was plotted against the stimulus frequency, a significant reduction in temporal resolution was apparent for EAAT5 ${ }^{-1}$ (gray curve, mean \pm SEM of 30 retinal pieces from 13 animals) compared with the WT (black curve, mean \pm SEM of 33 retinal pieces from 13 animals). Two-way ANOVA with Bonferroni multiple comparisons. Flicker stimulus: 610 activated rhodopsin molecules (rhod ${ }^{*}$ ) per rod and flash (rhod $/$ rod/flash); total stimulus duration: $3 \mathrm{~s}$; individual flash duration: $20 \mathrm{~ms}$.

seen between WT and EAAT5 ${ }^{-1-}$ retinae. Hence, targeted EAAT5 deletion does not produce gross pathologic changes in the retina. In conclusion, the EAAT5 ${ }^{-1-}$ mouse proved a good model to study the function of EAAT5 in generating and shaping light responses in the intact retina.

\section{EAAT5 improves temporal resolution in the retina}

Next, light responses were recorded from WT and EAAT5 ${ }^{-1-}$ retinae using MEAs under three light regimes: scotopic (dark-adapted, low-intensity stimuli, rods only), mesopic (dark-adapted, medium-intensity stimuli, rods and cones active), and photopic (light-adapted with bright background, high-intensity stimuli, cone dominated). Flicker stimuli were applied with frequencies of between
$2 \mathrm{~Hz}$ and $30 \mathrm{~Hz}$. Depending on the light regime, responses to flicker stimuli start to fuse at different frequencies (i.e., the flicker fusion frequency, which in mouse in all lighting regimes was found to be below $30 \mathrm{~Hz}$ ). Figure $4 A$ compares representative recordings of the LFP of darkadapted retinae from WT (left) and EAAT5 ${ }^{-1-}$ (right) animals when stimulated in the high mesopic range. The LFP recorded in vitro roughly corresponds to the electroretinogram (ERG) that can be recorded in vivo (Fujii et al., 2016). At light onset, a negative deflection was observed that corresponds to the a-wave of the ERG (mostly originating from the closure of cyclic nucleotide-gated ion channels in photoreceptors during the photoresponse), followed by a positive deflection corresponding to the b-wave (which reflects the activity of ON-bipolar cells). In both WT and EAAT5 $^{-1-}$ retinae at $2 \mathrm{~Hz}$, each successive light flash of 
A
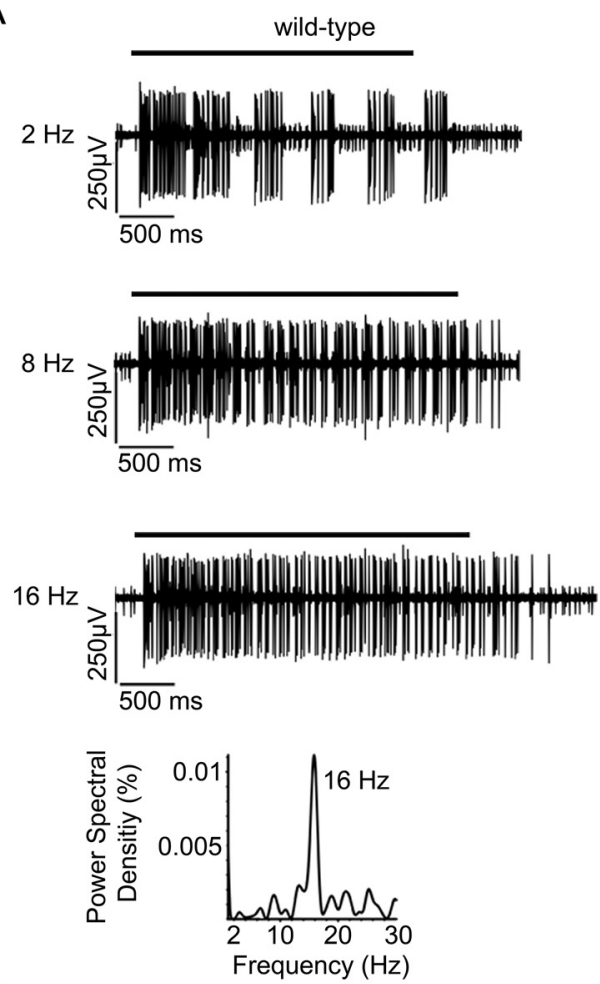
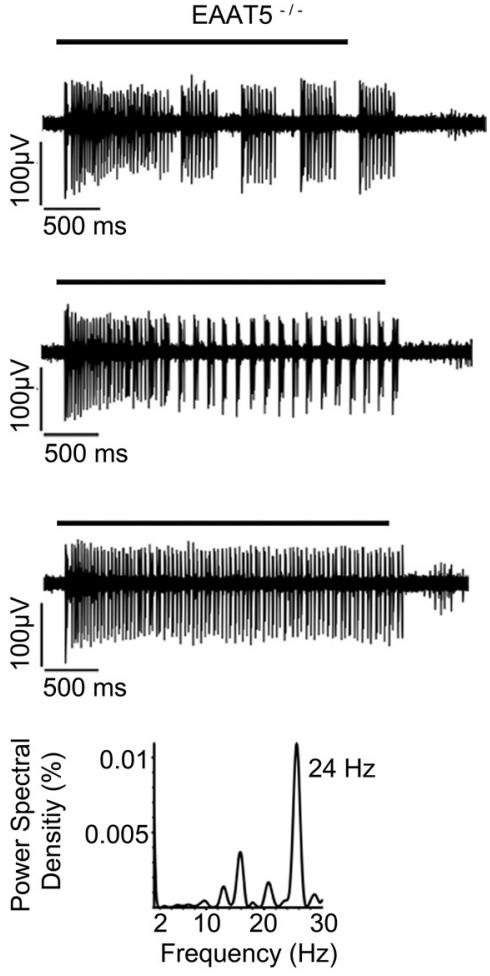

B

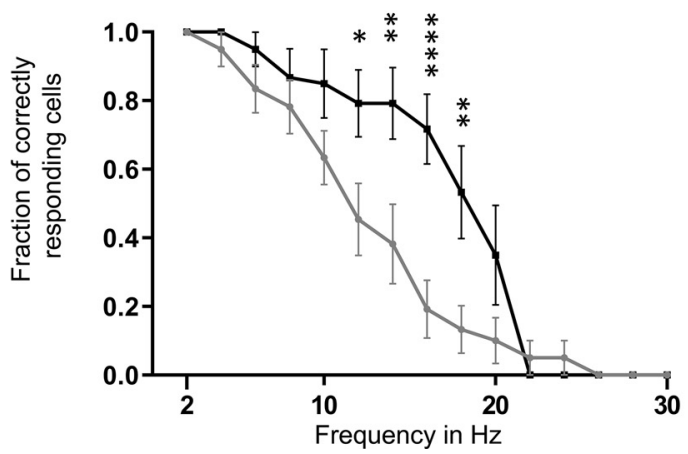

Figure 5. Temporal resolution of ON-ganglion cells is significantly impaired in the EAAT5 ${ }^{-1-}$ retina in the mesopic range. $\boldsymbol{A}$, Typical response of one type of ON-ganglion cell ("ON-merge cell") in the WT (left) and EAAT5 ${ }^{-/-}$retina (right). Bars: duration of flicker stimulus. $\boldsymbol{B}$, The fraction of correctly responding cells was significantly reduced in EAAT5 ${ }^{-1}$ (gray curve, mean \pm SEM of 32 cells of 10 animals) compared with WT (black curve, mean \pm SEM of 40 cells of 10 animals) cells at frequencies of 10-20 Hz. Two-way ANOVA with Bonferroni multiple comparisons. Flicker stimulus: 610 activated rhodopsin molecules (rhod $\left.{ }^{*}\right)$ per rod and flash (rhod $/ \mathrm{rod} /$ flash; mesopic conditions); total stimulus duration: $3 \mathrm{~s}$; individual flash duration: $20 \mathrm{~ms}$.

the flicker stimulus initiated additional deflections superimposed on the overall waveform triggered by the first flash. At $24 \mathrm{~Hz}$, retinae of neither genotype could resolve the flicker stimulus: both responses were consistent with the application of a continuous light stimulus. The WT retina could resolve the $10-\mathrm{Hz}$ flicker stimulus, with individual responses on top of the large deflection in LFP throughout the stimulus duration, albeit at a lower amplitude than at $2 \mathrm{~Hz}$. In contrast, these individual deflections could not be observed in the EAAT5 ${ }^{-1-}$ retina (i.e., this retina could not resolve the $10-\mathrm{Hz}$ flicker stimulus). For both WT and EAAT5 ${ }^{-1-}$ retinae, the fraction of correct responses was determined and plotted over the stimulus frequency (Fig. 4B). In EAAT5 ${ }^{-1-}$ retina (gray curve), temporal resolution was significantly compromised: half- maximal resolution was at $10 \mathrm{~Hz}$, compared with $14 \mathrm{~Hz}$ in the WT retina (black curve).

To test whether this difference also affects retinal output to the brain, the spiking behavior of ganglion cells was recorded. Up to 30 different types of ganglion cells are postulated in the mouse retina (Baden et al., 2016), each with a characteristic response behavior. Figure $5 A$ shows one type of response that was routinely recorded in this study both in WT (left) and EAAT5 ${ }^{-1-}$ (right) retina. In this ON-ganglion cell type, a 2-Hz flicker stimulus led to relatively long bursts triggered by the first two flashes in the first part of the response, which tended to merge ("ONmerge cell"); in the last two-thirds of the response, wellseparated bursts were triggered by every flash. Flicker stimuli of 2 and $8 \mathrm{~Hz}$ could be resolved in both genotypes. 


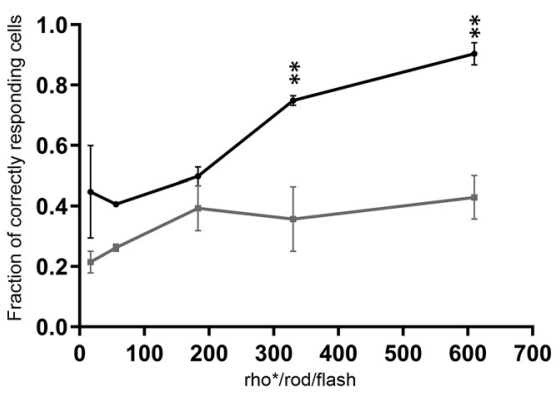

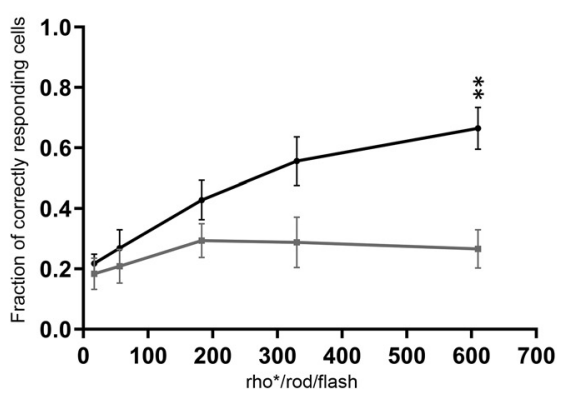

C

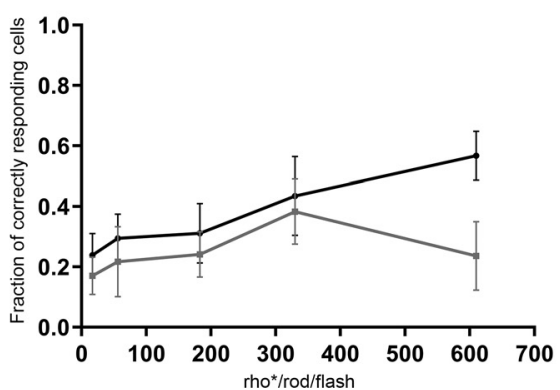

Figure 6. The impact of EAAT5 on temporal resolution in ganglion cells increases with stimulus intensity under mesopic conditions. Black curves: WT; gray curves: EAAT5 ${ }^{-1-}$. A, ON-merge cells (WT, 32 cells; EAAT5 ${ }^{-1-} 15$ cells). $\boldsymbol{B}$, ON-cells (except for ON-merge; WT, 92 cells; EAAT5 ${ }^{-1-} 96$ cells). C, OFF-cells (WT, 39 cells; EAAT5 ${ }^{-1-}, 20$ cells). Two-way ANOVA with Bonferroni multiple comparisons. Flicker stimulus: $12 \mathrm{~Hz}$, total stimulus duration: $3 \mathrm{~s}$; individual flash duration: $20 \mathrm{~ms}$. Stimulus intensities: 17, 56, 183, 330, 610 activated rhodopsin molecules (rhod ${ }^{*}$ ) per rod and flash (rhod*/rod/flash).

At $16 \mathrm{~Hz}$, the stimulus was well resolved in the WT cell (note the gaps separating the short bursts in the second half of the recording and the correct peak at $16 \mathrm{~Hz}$ in the power spectral density analysis shown below the trace) but not in the EAAT5 ${ }^{-1-}$ cell (very few gaps and a peak at $24 \mathrm{~Hz}$ instead of $16 \mathrm{~Hz}$ ). Plotting the fraction of correctly responding cells over the flicker frequency (Fig. 5B) revealed that temporal resolution by this cell type is significantly worse in $\mathrm{EAAT5}^{-1-}$ (gray curve) than WT (black curve) retina.

\section{The impact of EAAT5 on temporal resolution depends on stimulus intensity}

The bright light stimuli employed in these experiments (Figs. 4,5$)$ resulted in large changes in the membrane potential of photoreceptors and bipolar cells concomitant with large changes in the amount of glutamate released at the terminals of these cells. It is reasonable to assume that the impact of EAAT5 on the shaping of retinal light responses depends on the extent to which glutamate release is changed by the stimulus and, hence, on the stimulus intensity. Using a flicker frequency of $12 \mathrm{~Hz}$ (at which large differences were observed between responses of WT and EAAT5 ${ }^{-/-}$retina), retinae of both genotypes were stimulated at stimulus intensities from the scotopic to the high mesopic range. Figure 6 shows the fraction of correctly responding cells plotted against stimulus intensity for different ganglion cell types. For ONmerge cells (Fig. 6A), other ON-ganglion cell types (Fig. $6 B$, pooled $\mathrm{ON}$-ganglion cells except for $\mathrm{ON}$-merge cells), and OFF-ganglion cells (Fig. 6C) at low stimulus intensities, these values were small and differences between the two mouse genotypes were not significant. At the highest intensity, the fraction of correctly responding cells was larger in WT retina than in $\mathrm{EAAT5}^{-1-}$ retina. The difference was statistically significant for $\mathrm{ON}$ - but not for OFF-ganglion cells. With higher stimulus intensity, OFFganglion cells failed to respond to each flash of a flicker series, probably because they received more inhibition mediated by the rod bipolar/All pathway (Smith et al., 1986; Wässle et al., 1986; Müller et al., 1988). The failure to respond to each flash reduced their apparent flicker resolution.

Next, it was tested whether temporal resolution in the EAAT5 $^{-1-}$ was also compromised under photopic conditions. After light adaptation in vitro for $10 \mathrm{~min}$ to suppress the rod contribution and isolate cone-driven responses (Seeliger et al., 2011), the LFP waveform changed to resemble the characteristic ERG for light-adapted retinae (Fig. 7A). The large a-wave-like deflections were strongly reduced and the $b$-waves became shorter (compare Figs. $4 A$ and $7 A$ ).

In the light-adapted state, differences in temporal resolution of the two genotypes were much smaller than under mesopic conditions. As shown in Figure 7A, the retinae of both genotypes could resolve the $2-\mathrm{Hz}$ flicker stimulus equally well but not the $30-\mathrm{Hz}$ flicker stimulus. For the WT, amplitudes of the initial and successive b-waves were very similar for 2 - and $10-\mathrm{Hz}$ flicker stimuli; at $18 \mathrm{~Hz}$, the initial b-wave was twice as large as its successor. In the $\mathrm{EAAT5}^{-/-}$retina at $10 \mathrm{~Hz}$, amplitudes of the second and following b-waves were reduced by two-thirds compared with the initial b-wave; at $18 \mathrm{~Hz}$, the flicker stimulus was barely resolved. Recordings were performed at stimulus intensities of 1000 (Fig. 7B) and 19,000 (Fig. 7C) isomerizations per rod and flash. While there was a tendency for lower resolution in EAAT5 ${ }^{-1-}$ retina (gray curves) compared with WT retina (black curves), differences did not reach statistical significance under photopic conditions.

\section{Discussion}

This study introduces a new mouse model that enabled studying the impact of EAAT5 on retinal light responses in the intact retina for the first time. The major outcome of the study is: EAAT5 is highly localized in close proximity to the glutamate release sites at photoreceptor and bipolar cell synapses. Genetic ablation of EAAT5 severely affected retinal output by compromising temporal resolution.

\section{EAAT5 expression}

In rod bipolar cells, fluorescence staining showed bright puncta of EAAT5 at the axon terminal in retinal sections, 
A

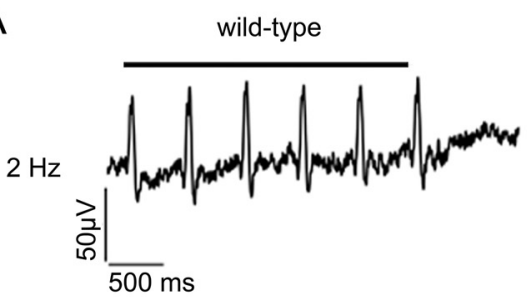

$10 \mathrm{~Hz}$
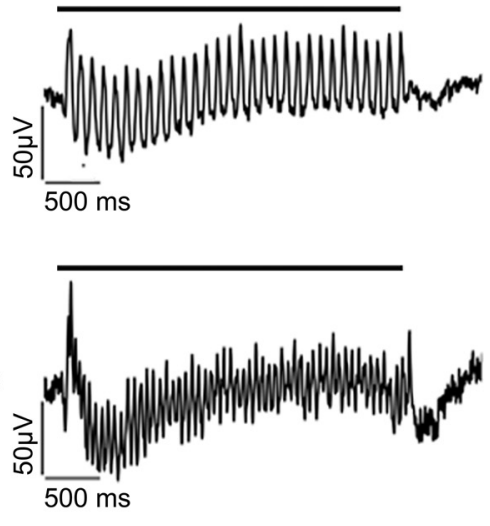

$\mathrm{B}$

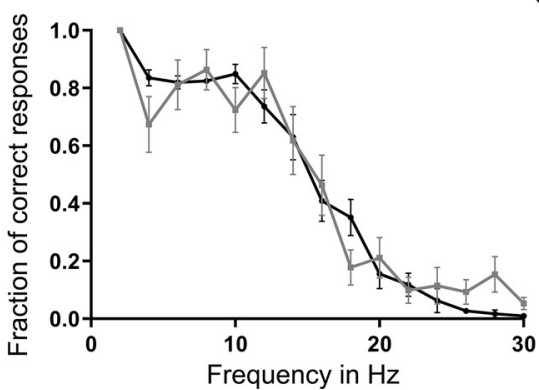

EAAT5
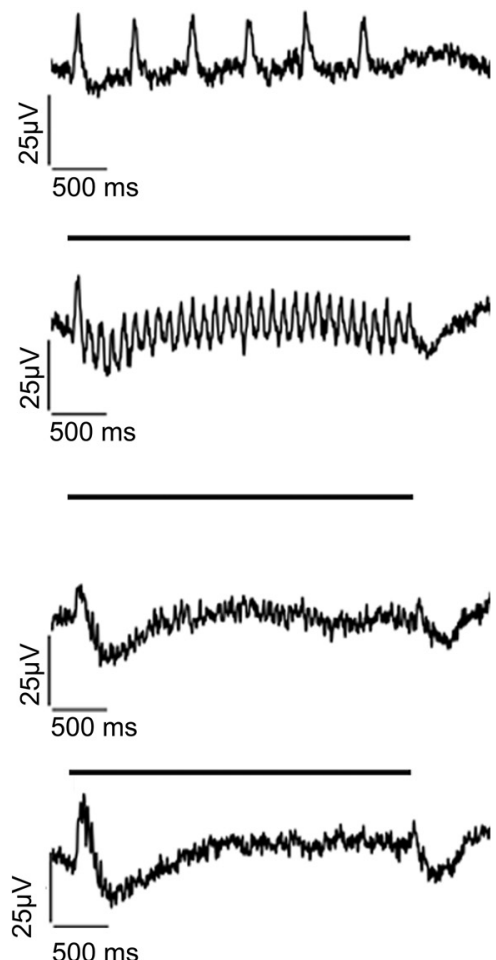

C

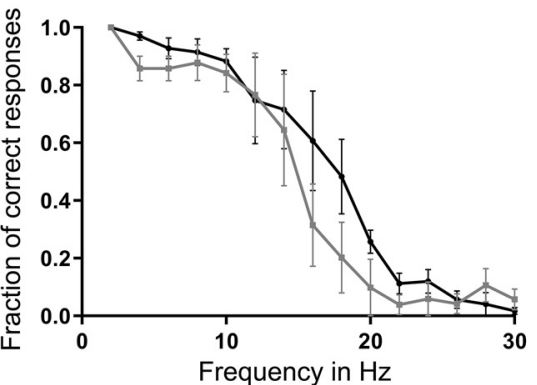

Figure 7. Temporal resolution of the EAAT5 $5^{-1}$ retina is not significantly impaired in the photopic range. Flicker stimuli were applied for a series of frequencies from 2 to $30 \mathrm{~Hz}$. A, For the 2-Hz flicker stimulus, both genotypes showed a clear response. The LFP of EAAT5 ${ }^{-1-}$ retina (right) showed slightly impaired temporal resolution for $10-$ and $18-\mathrm{Hz}$ flicker stimuli compared with the WT retina (left). Neither WT nor EAAT5 ${ }^{-1-}$ retinae could resolve the $30-\mathrm{Hz}$ flicker stimulus. Bars: stimulus duration. $\boldsymbol{B}$. The fraction of correct responses plotted against the stimulus frequency for stimulus intensity of 1000 activated rhodopsin molecules (rhod*/rod/flash) shows no significant reduction for EAAT5 ${ }^{-1-}$ (gray curve, mean \pm SEM of eight retinal pieces from six animals) compared with the WT (black curve, mean \pm SEM of 10 retinal pieces from six animals). Two-way ANOVA with Bonferroni multiple comparisons. C, The fraction of correct responses plotted against the stimulus frequency for stimulus intensity of 19,000 activated rhodopsin molecules $\left(\mathrm{rhod}^{*} / \mathrm{rod} / \mathrm{flash}\right)$ shows a mild but not significant reduction for EAAT5 ${ }^{-1-}$ (gray curve, mean \pm SEM of eight retinal pieces from six animals) compared with the WT (black curve, mean \pm SEM of 10 retinal pieces from six animals). Two-way ANOVA with Bonferroni multiple comparisons. Total stimulus duration: $3 \mathrm{~s}$; individual flash duration: $20 \mathrm{~ms}$; background light: 10,000 rhod*/rod/s.

as well as in dissociated cells. In the OPL, the situation is less clear. EAAT5 puncta in the invagination colocalized with neither the CabP28K marker of horizontal cell dendritic tips (Haverkamp and Wässle, 2000) nor with mGluR6 (on ON-bipolar cells). In the rat retina, mGluR6 localizes not to the extreme tip of ON-bipolar cell dendrites but more proximally, at $200-600 \mathrm{~nm}$ from the active zone of the invagination (Vardi et al., 2000). Thus, EAAT5 might localize more distally than mGluR6 on ON-bipolar cell dendrites. Unfortunately, rod bipolar cell markers (PKC $\alpha$ and $\mathrm{G} \alpha_{0}$ ) did not label dendrites distal to mGluR6, so colocalization with EAAT5 could not be tested (data not shown). Finally, EAAT5 might be expressed presynaptically in the photoreceptor membrane within the invagination. EAAT5 expression in photoreceptors was suggested previously (Eliasof and Werblin, 1993; Picaud et al., 1995; Pow and Barnett, 2000; Hasegawa et al., 2006; Wersinger et al., 2006; Lee et al., 2013). Tse et al. (2014) also 
reported punctate EAAT5 staining (using a commercial antibody) in the OPL of mouse retina, but did not associate these puncta with the glutamate release site. Using the same commercial antibody in double labeling experiments, $100 \%$ colocalization with the newly raised antiEAAT5 antibody was found (data not shown). Other studies on EAAT5 have described a more diffuse signal with no clear association with the glutamate release site (e.g., labeling of the entire terminal, somata, and even the inner segments of photoreceptors; Pow and Barnett, 2000; Wersinger et al., 2006). Of course, the antibodies used in these experiments have not yet been tested on EAAT5 ${ }^{-/-}$ retina.

\section{Function of EAAT5}

So far, the absence of an EAAT5-specific blocker has made it impossible to distinguish the functions of this transporter from those of other EAAT isoforms in the intact retina, in particular in shaping light responses. For example, in all previous studies EAAT-mediated currents in the retina were identified using EAAT blocker DL-threo$\beta$-benzyloxyaspartic acid (TBOA), which does not discriminate between EAAT isoforms. The kinetics of TBOAblockable currents in bipolar cells (Veruki et al., 2006) were not identical to those in cells with heterologously expressed EAAT5 (Gameiro et al., 2011; Schneider et al., 2014). These differences may depend on the recording conditions or reflect differences between the recorded cell types; however, the possibility that the results of previous studies may not reflect the function of EAAT5 alone, but may also include those of other EAAT isoforms (e.g., EAAT2 in bipolar cells; Rauen et al., 1996; Harada et al., 1998) cannot be excluded.

In this study, by establishing an EAAT5 $\mathrm{KO}$ mouse model, functions could be specifically attributed to this EAAT isoform. EAAT5 deletion specifically affected retinal output by compromising temporal resolution. EAAT5 might improve temporal resolution via different mechanisms: (1) glutamate-gated chloride currents mediated by EAAT5 could trigger feedback inhibition; (2) by buffering glutamate or clearing glutamate from the synaptic cleft, EAAT5 would reduce the action of glutamate at postsynaptic as well as on presynaptic glutamate receptors.

In neuronal networks, diverse feedback mechanisms adjust the gain control to limit the response amplitude (thereby preventing saturation of cellular and network activity) and increase temporal resolution by shortening the responses. In the retina, presynaptic and postsynaptic feedback mechanisms control every step of signal processing. An example of presynaptic feedback is activation of HCN1 channels (hyperpolarization-activated and cyclic nucleotide-gated ion channel 1) during the hyperpolarizing light response of photoreceptors, which effectively curtails the light response (Fain et al., 1978; Knop et al., 2008; Seeliger et al., 2011). Targeted deletion of HCN1 reduced flicker resolution and led to saturation of the retinal network by rod activity (Seeliger et al., 2011). EAAT5 might mediate another presynaptic feedback mechanism at retinal glutamatergic synapses that strongly improves temporal resolution. EAAT5 was found strategically localized for this function.

\section{EAAT5 in rod bipolar cells}

The effect of EAAT5 on temporal resolution was particularly pronounced under mesopic light conditions when both rods and cones are active but rods contribute a substantial fraction to the light response. Upon EAAT5 deletion, ON-ganglion cell spiking as well as b-waves of the LFP were strongly affected, both of which depend on rod bipolar cell activity. Characteristics of the b-wave can be affected by changing photoreceptor input to rod bipolar cells. For example, application of APB acting at mGluR6 at rod bipolar cell dendrites can abolish the bwave (Slaughter and Miller, 1981; Massey et al., 1983). Changing signal processing within the rod bipolar cells also affects the b-wave. For example, deletion of $\operatorname{PKC} \alpha$, which is highly expressed in rod bipolar cells, affects proper activation and termination of the rod bipolar cell responses and, hence, the characteristics of the bwave (Ruether et al., 2010; Xiong et al., 2015).

The effect of EAAT5 deletion is in perfect agreement with the postulated role of EAAT5 at rod bipolar cell terminals. First, EAAT5 was unequivocally localized in form of brightly fluorescent puncta to the output synapses in both sections and isolated rod bipolar cells. Second, EAAT5 was shown to act as glutamate-gated chloride channel in rod bipolar cells (Veruki et al., 2006; Wersinger et al., 2006; Bligard et al., 2020). Upon depolarization of the rod bipolar cell, glutamate release at the output synapse would activate not only the postsynaptic glutamate receptors but also presynaptic EAAT5, leading to chloride influx, hyperpolarization of the cell, and, consequently, reduced bipolar cell output. Indeed, chloride currents could be elicited by depolarization and were inhibited by TBOA, providing support for a postulated EAAT5-mediated feedback mechanism. Bligard et al. (2020) postulated that EAAT-mediated inhibition is important for gain control at the rod bipolar cell output synapse. Owing to the time delay needed for activation, EAAT5-mediated inhibition may preferentially affect the later stage of depolarization and, therefore, shorten rod bipolar cell output. Shorter signals would enable the transmission of higher frequencies at this synapse. Finally, flicker resolution is higher in the cone system than in the rod system. By reducing rod bipolar cell output under mesopic conditions, EAAT5-mediated feedback might shift the balance toward the cone system to enable higher flicker resolution. However, the improvement of temporal resolution might also depend on functions of EAAT5 apart from its function as a chloride channel. EAAT5 might improve glutamate buffering and reuptake in the synaptic cleft. This glutamate clearance would help to sharpen the action of glutamate at postsynaptic cells, thereby increasing temporal resolution in WT retina. In EAAT5 ${ }^{-1-}$ retina, at low stimulus frequencies used (e.g., at $2 \mathrm{~Hz}$ ), glutamate might diffuse from the synaptic cleft to be removed by EAAT1 and local glutamate concentration could return to baseline between individual light flashes even in the absence of EAAT5. At higher flicker frequencies, however, synaptic 
events might be considerably prolonged, thereby "blurring" synaptic activity and reducing temporal resolution.

Genetic ablation of EAAT5 only slightly lowered flicker resolution under photopic conditions (where the cone system dominates the light response). In electrophysiological experiments, no EAAT-like currents have been identified in mouse cone bipolar cells (Wersinger et al., 2006; Bligard et al., 2020). However, since there are at least 12 types of cone bipolar cells (for review, see Euler et al., 2014) and bipolar cells can differ substantially in their inventory of ion channels (Ivanova and Müller, 2006), the small samples of recorded cells in these studies might not have included all bipolar cell types. Some EAAT5-immunoreactive puncta were associated with cone bipolar cell terminals (Fig. $3 A$ ). Based on their stratification level in the IPL, some of these terminals might correspond to type five cone bipolar cells, which are ON-cone bipolar cells. EAAT5-like immunoreactivity in some cone bipolar cells was also reported by Pow and Barnett (2000) and FykKolodziej et al. (2004). Thus, while the evidence of EAAT5 expression is less compelling for cone bipolar axon terminals and EAAT5 seems to be of lesser importance for photopic vision, immunohistochemical data suggest that EAAT5 might play a role in controlling synaptic output at least in some cone bipolar cell types.

\section{EAAT5 in the outer retina}

There is also evidence for EAAT5 expression in photoreceptor terminals (this study; see also Eliasof and Werblin, 1993; Picaud et al., 1995; Pow and Barnett, 2000; Hasegawa et al., 2006; Wersinger et al., 2006; Lee et al., 2013). Photoreceptor synapses show a complex organization and multiple feedback mechanisms at these synapses have been described. Therefore, the physiological role of EAAT5 and the effect of EAAT5 deletion in the outer retina are more difficult to interpret than in the inner retina. Although EAAT5 is considered a glutamate transporter with a low transport rate (Gameiro et al., 2011; Schneider et al., 2014), Hasegawa et al. (2006) reported that glutamate clearance at the photoreceptor synapse mediated by EAAT5 is important for shaping of light responses at the rod-rod bipolar cell synapse in mice. KO of EAAT5 in photoreceptors might lead to elevated levels of glutamate in the synaptic cleft, triggering a variety of possible effects. For example, a mGluR was reported on cone terminals that might become activated and could affect the rate of glutamate release (Van Hook et al., 2017). Depolarization of horizontal cells by increased glutamate levels would affect photoreceptor output in a complex manner. For example, feedback by horizontal cells does not only affect photoreceptor membrane potential but also causes changes in peak amplitude as well as a shift in the voltage-dependence of cone calcium channels (Verweij et al., 1996; for review, see Thoreson and Mangel, 2012; Wen and Thoreson, 2019). Finally, EAAT5 might affect photoreceptor output via its function as chloride channel. Measurements of the chloride reversal potential in salamander (Thoreson and Bryson, 2004) and mammalian cones (Szmajda and DeVries, 2011) indicate a relatively positive chloride Nernst potential, which would argue against a negative feedback. Moreover, in a substantial body of work on salamander photoreceptors, Thoreson and colleagues speculated that chloride dynamics in the photoreceptor terminal affect the activation properties of voltage-activated calcium channels (Thoreson et al., 2000, 2003; Thoreson and Bryson, 2004; Li et al., 2008). Activation of EAAT5 triggers a chloride conductance that might affect the chloride concentration in the small terminal, and hence, photoreceptor output. This delicate interaction would be suited to fine tune photoreceptor output and must be determined in future studies.

In summary, the mechanisms by which EAAT5 could affect information transfer in outer retinal synapses are quite diverse and more experiments, in particular involving single-cell recordings or paired recordings of photoreceptors, horizontal cells, and bipolar cells are required to address this question. This is well beyond the scope of the present study that focused on the introduction and characterization of a new mouse model to study EAAT5 function, thereby overcoming the lack of an EAAT5-specific inhibitor. The mouse model enabled to demonstrate for the first time the role of EAAT5 in the intact retina. EAAT5 considerably increases temporal resolution of the retina. EAAT5 was found highly localized to glutamatergic ribbon synapses in both synaptic layers, consistent with a role in shaping the output of glutamatergic cells in the retina. Interestingly, EAAT5 is also expressed at the ribbon synapses of vestibular hair cells (Dalet et al., 2012) but not at the calyx of Held (Palmer et al., 2003), a well-studied conventional glutamatergic synapse. Synaptic activity in ribbon synapses is based on graded potentials of the presynaptic cell and is typically associated with much higher, sustained vesicular release compared with conventional more transient synapses. It is, therefore, tempting to speculate that EAAT5-mediated feedback triggered by glutamate release might be a common mechanism to regulate synaptic output at ribbon synapses.

\section{References}

Baden T, Berens P, Franke K, Román Rosón M, Bethge M, Euler T (2016) The functional diversity of retinal ganglion cells in the mouse. Nature 529:345-350.

Bligard GW, DeBrecht J, Smith RG, Lukasiewicz PD (2020) Lightevoked glutamate transporter EAAT5 activation coordinates with conventional feedback inhibition to control rod bipolar cell output. J Neurophysiol 123:1828-1837.

Dalet A, Bonsacquet J, Gaboyard-Niay S, Calin-Jageman I, Chidavaenzi RL, Venteo S, Desmadryl G, Goldberg JM, Lysakowski A, Chabbert C (2012) Glutamate transporters EAAT4 and EAAT5 are expressed in vestibular hair cells and calyx endings. PLoS One 7:e46261.

Derouiche A, Rauen T (1995) Coincidence of L-glutamate/L-aspartate transporter (GLAST) and glutamine synthetase (GS) immunoreactions in retinal glia: evidence for coupling of GLAST and GS in transmitter clearance. J Neurosci Res 42:131-143.

Dowling J, Boycott B (1966) Organization of the primate retina: electron microscopy. Proc R Soc Lond B Biol Sci 166:80-111.

Eliasof S, Werblin F (1993) Characterization of the glutamate transporter in retinal cones of the tiger salamander. J Neurosci 13:402411. 
Euler T, Haverkamp S, Schubert T, Baden T (2014) Retinal bipolar cells: elementary building blocks of vision. Nat Rev Neurosci 15:507-519.

Fahlke C, Kortzak D, Machtens JP (2016) Molecular physiology of EAAT anion channels. Pflugers Arch 468:491-502.

Fain GL, Quandt FN, Bastian BL, Gerschenfeld HM (1978) Contribution of a caesium-sensitive conductance increase to the rod photoresponse. Nature 272:466-469.

Fujii M, Sunagawa GA, Kondo M, Takahashi M, Mandai M (2016) Evaluation of micro electroretinograms recorded with multiple electrode array to assess focal retinal function. Sci Rep 6:30719.

Fyk-kolodziej B, Qin PU, Dzhagaryan A, Pourcho RG (2004) Differential cellular and subcellular distribution of glutamate transporters in the cat retina. Vis Neurosci 21:551-565.

Gameiro A, Braams S, Rauen T, Grewer C (2011) The discovery of slowness: low-capacity transport and slow anion channel gating by the glutamate transporter EAAT5. Biophys J 100:2623-2632.

Greferath U, Grünert U, Wässle H (1990) Rod bipolar cells in the mammalian retina show protein kinase $\mathrm{C}$-like immunoreactivity. $\mathrm{J}$ Comp Neurol 301:433-442.

Harada T, Harada C, Watanabe M, Inoue Y, Sakagawa T, Nakayama N, Sasaki S, Okuyama S, Watase K, Wada K, Tanaka K (1998) Functions of the two glutamate transporters GLAST and GLT-1 in the retina. Proc Natl Acad Sci USA 95:4663-4666.

Hasegawa J, Obara T, Tanaka K, Tachibana M (2006) High-density presynaptic transporters are required for glutamate removal from the first visual synapse. Neuron 50:63-74.

Haverkamp S, Wässle H (2000) Immunocytochemical analysis of the mouse retina. J Comp Neurol 23:1-23.

Haverkamp S, Ghosh KK, Hirano AA, Wässle H (2003) Immunocytochemical description of five bipolar cell types of the mouse retina. J Comp Neurol 455:463-476.

Ivanova E, Müller F (2006) Retinal bipolar cell types differ in their inventory of ion channels. Vis Neurosci 23:143-154.

Izumi Y, Shimamoto K, Benz AM, Hammerman SB, Olney JW, Zorumski CF (2002) Glutamate transporters and retinal excitotoxicity. Glia 39:58-68.

Knop GC, Seeliger MW, Thiel F, Mataruga A, Kaupp UB, Friedburg C, Tanimoto N, Müller F (2008) Light responses in the mouse retina are prolonged upon targeted deletion of the HCN1 channel gene. Eur J Neurosci 28:2221-2230.

Kugler P, Beyer A (2003) Expression of glutamate transporters in human and rat retina and rat optic nerve. Histochem Cell Biol 120:199-212.

Lee A, Anderson AR, Stevens M, Beasley S, Barnett NL, Pow DV (2013) Excitatory amino acid transporter 5 is widely expressed in peripheral tissues. Eur J Histochem 57:11-71.

Lehre KP, Davanger S, Danbolt NC (1997) Localization of the glutamate transporter protein GLAST in rat retina. Brain Res 744:129137.

Li B, McKernan K, Shen W (2008) Spatial and temporal distribution patterns of $\mathrm{Na}-\mathrm{K}-2 \mathrm{Cl}$ cotransporter in adult and developing mouse retinas. Vis Neurosci 25:109-123.

Lyubarsky AL, Daniele LL, Pugh EN (2004) From candelas to photoisomerizations in the mouse eye by rhodopsin bleaching in situ and the light-rearing dependence of the major components of the mouse ERG. Vision Res 44:3235-3251.

Machtens JP, Kortzak D, Lansche C, Leinenweber A, Kilian P, Begemann B, Zachariae U, Ewers D, de Groot BL, Briones R, Fahlke C (2015) Mechanisms of anion conduction by coupled glutamate transporters. Cell 160:542-553.

Massey SC, Redburn DA, Crawford MLJ (1983) The effects of 2amino-4-phosphonobutyric acid (APB) on the ERG and ganglion cell discharge of rabbit retina. Vision Res 23:1607-1613.

Mim C, Balani P, Rauen T, Grewer C (2005) The glutamate transporter subtypes EAAT4 and EAATs 1-3 transport glutamate with dramatically different kinetics and voltage dependence but share a common uptake mechanism. J Gen Physiol 126:571-589.

Müller F, Wässle H, Voigt T (1988) Pharmacological modulation of the rod pathway in the cat retina. J Neurophysiol 59:1657-1672.
Negishi K, Kato S, Teranishi T (1988) Dopamine cells and rod bipolar cells contain protein kinase $\mathrm{C}$-like immunoreactivity in some vertebrate retinas. Neurosci Lett 94:247-252.

Nomura A, Shigemoto R, Nakamura Y, Okamoto N, Mizuno N, Nakanishi S (1994) Developmentally regulated postsynaptic localization of a metabotropic glutamate receptor in rat rod bipolar cells. Cell 77:361-369.

Palmer MJ, Taschenberger H, Hull C, Tremere L, von Gersdorff H (2003) Synaptic activation of presynaptic glutamate transporter currents in nerve terminals. J Neurosci 23:4831-4841.

Picaud SA, Larsson HP, Grant GB, Lecar H, Werblin FS (1995) Glutamate-gated chloride channel with glutamate-transporter-like properties in cone photoreceptors of the tiger salamander. $J$ Neurophysiol 74:1760-1771.

Pow D, Barnett NL (1999) Changing patterns of spatial buffering of glutamate in developing rat retinae are mediated by the Muller cell glutamate transporter GLAST. Cell Tiss Res 297:57-66.

Pow D, Barnett NL (2000) Developmental expression of excitatory amino acid transporter 5: a photoreceptor and bipolar cell glutamate transporter in rat retina. Neurosci Lett 280:21-24.

Rauen T, Rothstein JD, Wässle H (1996) Differential expression of three glutamate transporter subtypes in the rat retina. J Comp Neurol 286:325-336.

Rauen T, Taylor WR, Kuhlbrodt K, Wiessner M (1997) High-affinity glutamate transporters in the rat retina: a major role of the glial glutamate transporter GLAST-1 in transmitter clearance. Cell Tiss Res 291:19-31.

Rauen T, Wiessner M, Sullivan R, Lee A, Pow DV (2004) A new GLT1 splice variant: cloning and immunolocalization of GLT1c in the mammalian retina and brain. Neurochem Int 45:1095-1106.

Regus-Leidig H, Ott C, Löhner M, Atorf J, Fuchs M, Sedmak T, Kremers J, Fejtová A, Gundelfinger ED, Brandstätter JH (2013) Identification and immunocytochemical characterization of piccolino, a novel piccolo splice variant selectively expressed at sensory ribbon synapses of the eye and ear. PLoS One 6:e70373.

Rose CR, Ziemens D, Untiet V, Fahlke C (2018) Molecular and cellular physiology of sodium-dependent glutamate transporters. Brain Res Bull 136:3-16.

Ruether K, Feigenspan A, Pirngruber J, Leitges M, Baehr W, Strauss O (2010) PKC $\alpha$ is essential for the proper activation and termination of rod bipolar cell response. Invest Ophthalmol Vis Sci 51:6051-6058.

Sarthy VP, Pignataro L, Pannicke T, Weick M, Reichenbach A, Harada T, Tanaka K, Marc R (2005) Glutamate transport by retinal Müller cells in glutamate/aspartate transporter-knockout mice. Glia 49:184-196.

Seeliger MW, Brombas A, Weiler R, Humphries P, Knop G, Tanimoto N, Müller $F$ (2011) Modulation of rod photoreceptor output by $\mathrm{HCN} 1$ channels is essential for regular mesopic cone vision. Nat Commun 2:532.

Schneider N, Cordeiro S, Machtens JP, Braams S, Rauen T, Fahlke C (2014) Functional properties of the retinal glutamate transporters GLT-1c and EAAT5. J Biol Chem 289:1815-1824.

Slaughter MM, Miller RF (1981) 2-Amino-4-phosphonobutyric acid: a new pharmacological tool for retina research. Science 211:182185.

Smith RG, Freed M, Sterling P (1986) Microcircuitry of the darkadapted cat retina: functional architecture of the rod-cone network. J Neurosci 6:3505-3517.

Szmajda BR, Devries SH (2011) Glutamate spillover between mammalian cone photoreceptors. J Neurosci 31:13431-13441.

Torres-Salazar D, Fahlke C (2007) Neuronal glutamate transporters vary in substrate transport rate but not in unitary anion channel conductance. J Biol Chem 282:34719-34726.

Thoreson WB, Bryson EJ (2004) Chloride equilibrium potential in salamander cones. BMC Neurosci 5:53.

Thoreson WB, Mangel SC (2012) Lateral interactions in the outer retina. Prog Retin Eye Res 31:407-441.

Thoreson WB, Nitzan R, Miller RF (2000) Chloride efflux inhibits single calcium channel open probability in vertebrate photoreceptors: 
chloride imaging and cell-attached patch-clamp recordings. Vis Neurosci 17:197-206.

Thoreson WB, Bryson EJ, Rabl K (2003) Reciprocal interactions between calcium and chloride in rod photoreceptors. J Neurophysiol 90:1747-1753.

Tse DY, Chung I, Wu SM (2014) Possible roles of glutamate transporter EAAT5 in mouse cone depolarizing bipolar cell light responses. Vision Res 103:63-74.

Vandenberg RJ, Ryan RM (2013) Mechanisms of glutamate transport. Physiol Rev 93:1621-1657.

Van Hook MJ, Babai N, Zurawski Z, Yim YY, Hamm HE, Thoreson WB (2017) A presynaptic group III mGluR recruits Gby/SNARE interactions to inhibit synaptic transmission by cone photoreceptors in the vertebrate retina. J Neurosci 37:4618-4634.

Vardi N, Duvoisin R, Wu G, Sterling P (2000) Localization of mGluR6 to dendrites of ON bipolar cells in primate retina. J Comp Neurol 423:402-412.

Veruki ML, Mørkve SH, Hartveit E (2006) Activation of a presynaptic glutamate transporter regulates synaptic transmission through electrical signaling. Nat Neurosci 9:1388-1396.
Verweij J, Kamermans M, Spekreijse H (1996) Horizontal cells feed back to cones by shifting the cone calcium-current activation range. Vision Res 36:3943-3953.

Wässle H, Schäfer-Trenkler I, Voigt T (1986) Analysis of a glycinergic inhibitory pathway in the cat retina. J Neurosci 6:594604.

Wen X, Thoreson WB (2019) Contributions of glutamate transporters and $\mathrm{Ca} 2+$-activated $\mathrm{Cl}$ - currents to feedback from horizontal cells to cone photoreceptors. Exp Eye Res 189:107847.

Wersinger E, Schwab Y, Sahel JA, Rendon A, Pow DV, Picaud S, Roux MJ (2006) The glutamate transporter EAAT5 works as a presynaptic receptor in mouse rod bipolar cells. J Physiol 577:221234.

Wyszecki G, Stiles WS (2000) Color Science: concepts and methods, quantitative data and formulae, Ed 2. New York: Wiley, Inc.

Xiong WH, Pang JJ, Pennesi MER, Duvoisin RM, Wu SM, Morgans CW (2015) The effect of PKC $\alpha$ on the light response of rod bipolar cells in the mouse retina. Invest Ophthalmol Vis Sci 56:49614974. 